\title{
Gall bladder stone formation in the postoperative first year after sleeve gastrectomy
}

\author{
Mehmet Buğra Bozan
}

Department of Surgery, Kahramanmaraş Sütçü İmam University, Kahramanmaraş, Turkey

\begin{abstract}
Introduction: This study aims to evaluate the incidence of cholelithiasis formation in the postoperative first year of patients who underwent laparoscopic sleeve gastrectomy.

Materials and Methods: The first 100 consecutive patients operated for morbid obesity between January 2016 and January 2017 by the same surgeon were retrospectively evaluated. One patient who underwent laparoscopic mini-gastric bypass and seven patients who had previously undergone cholecystectomy or underwent concomitant cholecystectomy were excluded from this study, and 92 patients who underwent sleeve gastrectomy were included. Demographic data (age, sex), changes in body mass index (BMI), new cholelithiasis formation in the postoperative period, in preoperative period presence of diabetes mellitus (DM) and helicobacter like organism (HLO) positivity were examined. Student's t-test or Mann-Whitney U test was used to compare numerical data, and the chi-square test was used to evaluate categorical data.
\end{abstract}

Results: The preoperative mean age of patients was $36.16 \pm 9.8(18-58)$ years and mean BMI was $45.09 \pm 4.96$ $(37-67.1) \mathrm{kg} / \mathrm{m}^{2}$. Male/Female rate was $15 / 77$. There is no statistically significant difference between postoperative cholelithiasis formation and gender $(p>0.05)$. There is no statistically significance between postoperative cholelithiasis formation and preoperative DM presence $(p>0.05)$. There is statistically significance between postoperative cholelithiasis formation and preoperative HLO positivity $(p<0.05)$. Cholesistectomy was performed for symptomatic eight patients (8.7\%). There is no statistically significant between patients with or without postoperative cholelithiasis formation for BMI changes between preoperative values and postoperative follow-up ( $p>0.05)$.

Conclusion: The formation of cholelithiasis is an important complication of bariatric surgery, but quick weight loss does not have an effect on cholelithiasis. Cholesistectomy should not be performed until symptomatic cholelithiasis. Preoperative HLO eradication can diminish the formation of the cholelithiasis.

Keywords: Cholesistolithiasis; laparoscopic sleeve gastrectomy; morbid obesity; postoperative complication.

\section{Introduction}

Obesity is an important health problem worldwide with increasing rates. One of every five people in the world and in our country is suffering from obesity. Comorbid diseases (such as diabetes, hypertension, chronic obstruc- tive pulmonary disease) are the most important factors for obesity to be a health problem in itself. ${ }^{[1,2]}$ Complications due to these comorbidities decrease with the treatment of obesity. ${ }^{[3]}$ Bariatric surgery is the most effective treatment option for the morbid obesity, although medical treatment 
is used in the treatment of obesity. ${ }^{[2]}$ In the development process of bariatric surgery sleeve gastrectomy (SG) was first step of biliopancreatic diversion-duodenal switch surgery initially but then SG become the most performed bariatric procedure for morbid obesity in the world and Turkey. ${ }^{[2]}$ With increasing numbers of SG, complications due to SG increased. Gallstone formation is an important complication after SG. Rapid loss of weight can lead increase in cholelithiasis due to saturation of cholesterol and consantration of musine as the mechanism in normal population. ${ }^{[4]}$ Additionally low calory diet, female sex, motility disorders of gallbladder increases the formation of cholelithiasis. ${ }^{[5]}$

The aim of this study was to evaluate the incidence of cholelithiasis formation in the first postoperative year of patients who underwent laparoscopic sleeve gastrectomy.

\section{Materials and Methods}

The first 100 consecutive patients operated for morbid obesity between January 2016 and January 2017 by the same surgeon were retrospectively evaluated. Exclusion criterias; different types of bariatric surgery, preoperatively operated patients for cholelithiasis, concomitant cholesistectomy with sleeve gastrectomy, patients whom data can not be reached. One patient who underwent laparoscopic mini-gastric bypass and 7 patients who had previously undergone cholecystectomy or underwent concomitant cholecystectomy were excluded and 92 patients who underwent sleeve gastrectomy were included.

Preoperative values and early postoperative data were obtained from hospital computer records and patient followup charts. Patients' postoperative first year the imaging findings (ultrasonography), weight and body mass index (BMI) values were obtained by contacting the patients via social media (WhatsApp, Facebook, Messenger). Demographic data of the patients (age, gender), BMI changes, formation of new gallbladder stones in postoperative period, preoperative presence of type 2 diabetes mellitus (DM) and helicobacter like organism (HLO) positivity were examined.

SPSS 20 were used for statistical analyses. In comparison of numerical data for normality was evaluated according to Kolmogorow-Simirnow or Shapiro-Wilk Test. Student ttest or Mann-Whitney $u$ test were used to evaluate the numerical data under normality of distrubution. Chi-square test was used to evaluate categorical data. Pearson chisquare or Fischer's exact test was used according to the normality tests. Data were given as mean \pm standard deviation (SD) (minimum-maximum).

\section{Results}

Preoperative mean age and BMI values of patients were $36.16 \pm 9.8(18-58)$ years and $45.09 \pm 4.96(37-67.1) \mathrm{kg} / \mathrm{m}^{2}$. Male/female rate was 15/77 (16.3\%/83.7\%). Preoperative mean age and BMI values of male patients were $37.47 \pm 7.83$ (26-49) years and $48.32 \pm 7.72(39.6-64.5) \mathrm{kg} / \mathrm{m}^{2}$. Preoperative mean age and BMI values of female patients were $36.29 \pm 10.21$ (37-67) years and 44.59 $\pm 4.26(37-67.1) \mathrm{kg} / \mathrm{m}^{2}$.

There was no statistically significant difference was seen between gender or presence of DM preoperatively and the formation of postoperative cholelithiasis ( $p>0.05$ for both two values). There was statistically significant difference was seen between preoperative HLO positivity and postoperative cholelithiasis formation $(\mathrm{p}<0.05$; coefficient: 0.298) (Table 1). Cholecystectomy was performed for symptomatic 8 patients $(8.7 \%)$ whom new cholelithiasis formation were seen in postoperative first year of SG.

There was no significant difference between patients with or without gallbladder stones formation in BMI values for preoperative and postoperative follow-up (3, 6, 9 and 12 months) ( $p$ values respectively; $0.775 ; 0.144 ; 0.659 ; 0.235$ ve 0.404) (Fig. 1).

Of the 15 patients who developed cholelithiasis in the first year postoperatively, 5 (5.4\%) were seen in the 3 months controls; 6 were seen $(6.5 \%)$ in the $6^{\text {th }}$ month controls; 2 $(2.2 \%)$ were seen in the $9^{\text {th }}$ month controls and $2(2.2 \%)$ were seen in the $12^{\text {th }}$ month controls.

\section{Discussion}

The incidence of gallbladder-related disease varies from $5.9 \%$ to $21.6 \% .^{[5,6]}$ Approximately one of 5 patients with cholelithiasis are symptomatic and they experience pain and complications. ${ }^{[7]}$ The incidence of gallstone formation in obese patients increases three to five times of the normal population. ${ }^{[5,8]}$ Short bowel syndrome, diabetes, and previous gastrointestinal surgeries are also seen as risk factors for gallstone formation. ${ }^{[8-11]}$ Additionally due to biliary stasis or incomplete emptying of the gallbladder causes increased risk. ${ }^{[10,12]}$ However, in our study, no significant difference was found between gallstone formation after SG and the presence of type $2 \mathrm{DM}$ in the preoperative period. This difference was thought to be related to the improvement of comorbid diseases after bariatric and 
Table 1. Preoperative DM and HLO positivity, sex for postoperative cholelithiasis formation after the first year of SG

Postoperative cholelithiasis formation after the first year of SG

\begin{tabular}{|c|c|c|c|c|c|c|}
\hline \multicolumn{2}{|c|}{$(+)$} & \multicolumn{2}{|c|}{$(-)$} & \multicolumn{2}{|c|}{ Total } & \multirow[t]{2}{*}{$\mathbf{p}$} \\
\hline $\mathbf{n}$ & $\%$ & $\mathbf{n}$ & $\%$ & $n$ & $\%$ & \\
\hline 2 & 2.2 & 13 & 14.1 & 15 & 16.3 & 0.541 \\
\hline 13 & 14.1 & 64 & 69.6 & 77 & 83.7 & \\
\hline 3 & 3.3 & 15 & 16.3 & 18 & 19.6 & 0.602 \\
\hline 12 & 13 & 62 & 67.4 & 74 & 80.4 & \\
\hline 8 & 8.7 & 14 & 15.2 & 22 & 23.9 & $0007 *$ \\
\hline 7 & 7.6 & 63 & 68.5 & 70 & 76.1 & \\
\hline
\end{tabular}

SG: Sleeve gastrectomy; $* p<0.05$.

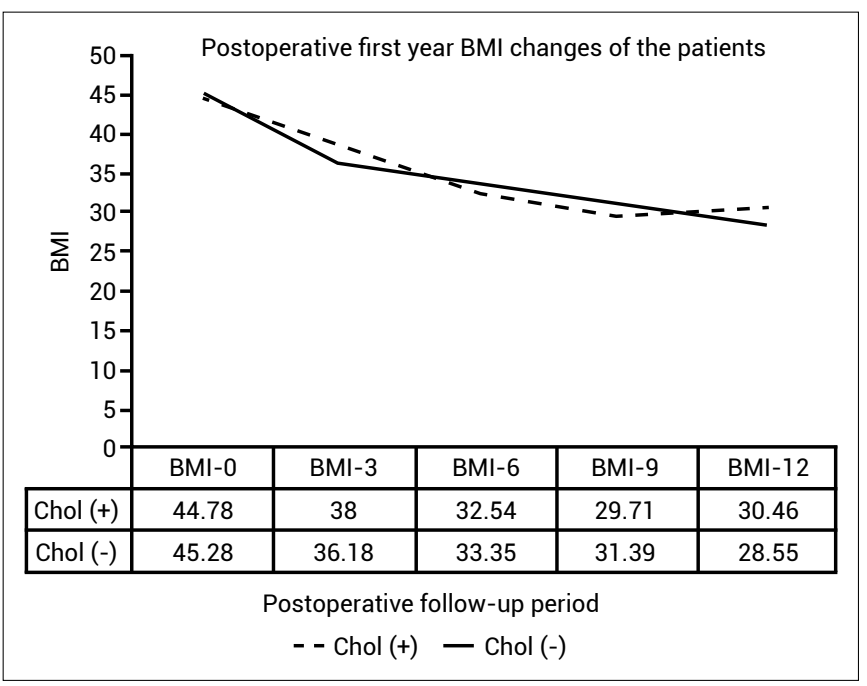

Figure 1. BMI changes between with or without cholelithiasis formation after the first year of SG.

Chol: Cholelithiasis; BMI: Body Mass Index.

metabolic surgeries.

Gallbladder stone formation rates increase in patients undergoing obesity surgery due to rapid weight loss (especially those who lose weight over $1.5 \mathrm{~kg}$ per week). ${ }^{[5,8,13]} \mathrm{In}$ our study, new gallbladder stone formation was seen 11 of the 15 patients, whom new cholelithiasis formation after SG was seen, in the rapid weight loss of the 6 months. However there was no significance between postoperative BMI changes and gallbladder stone formation as Ozdaş et al. ${ }^{[14]}$ and Manatsathit et al.'s ${ }^{[15]}$ studies.

Although all bariatric surgeries are associated with gallstone formation (gallstone prevalence 28 to $71 \%$ in pa- tients undergoing bariatric surgery), the type of bariatric surgery also leads to an increase in gallstone formation. The formation of cholelithiasis is less common after restrictive bariatric surgeries (6-7\% for laparoscopic gastric band and $20-28 \%$ for laparoscopic SG), therefore the risk of cholelithiasis formation more common increases after bariatric surgeries such as roux-n-y gastric bypass (38$52 \%)$ where enterohepatic circulation and normal gallbladder physiology are impaired. ${ }^{[12,16-20]}$ In our study, the postoperative new cholelithiasis formation was observed in $15(16.3 \%)$ of 92 patients included and this result was lower than the literature. This lower rate was thought to be related to the shorter postoperative follow up period than in other studies.

There is an significant relation between HLO infection and gallbladder stones in normal population. This is related with bile duct and gallbladder were being target for chronic HLO infection. The eradication of Helicobacter pylori (HP) showed to diminish gallbladder stone formation. ${ }^{[20]}$ Takahashi et al. ${ }^{[2]}$ were found an positive relation with HP and gallbladder stones. Similarly, in our study, a significant correlation was found between the preoperative HP positivity and postoperative gallstone. Because of this significant relationship, we suggest that preoperative eradication therapy of HP may decrease the rate of cholelithiasis formation after bariatric surgery.

Treatment of gallstones in patients undergoing bariatric surgery varies. While some groups recommend concomitant cholecystectomy with primary surgery, it is generally 
recommended that patients with symptomatic gallstones be operated if new gallbladder stone formation is seen after bariatric surgery. ${ }^{[22-27]}$ O'Brien et al. ${ }^{[16]}$ recommends concomitant cholecystectomy for gastric bypass patients and does not recommend concomitant cholecystectomy for laparascopic adjastable gastric band patients. Tsirline et al. ${ }^{[24]}$ mentioned that their study didn't support prophylactic cholecystectomy for bariatric surgery patients. Raziel et al. ${ }^{[25]}$ doesn't recommend prophylactic cholecystectomy for bariatric patients without concomitant cholelithiasis because of an increase in postoperative complication risk. Sioka et al. ${ }^{[26]}$ showed that the incidence of syptomatic cholelithiasis is $5.7 \%$. For this reason they recommend concomitant cholecystectomy for LSG patients because of comorbidities. Few studies recommend the use of ursodeoxycholic acid in the first 6 to 12 months postoperatively to prevent gallstone formation. ${ }^{[19,27]}$ Frequent ultrasonographic follow-up is also recommended to prevent complications. ${ }^{[23]}$ In our study, the patients underwent ultrasonographic examination in the first postoperative year for 3 months in order to determine formation of cholelithiasis. Eightsymptomatic patients operated and 7 asymtptomatic patients were not operated. The symptomatic cholelithiasis incidance of our study is $8.7 \%$ and this is slightly higher than normal population but this rate doesn't support concomitant cholecystectomy for LSG patients.

In conclusion, gallbladder stone formation is an important complication of bariatric surgery. Prophylactic cholecystectomy should not be performed unless it becomes symptomatic in bariatric surgical procedures. The eradication therapy of preoperative HLO positive patients may decrease the cholelithiasis formation after bariatric surgery.

This study was presented as an oral presentation ("First 100 Cases of a New Bariatric Surgeon: What Did I Learn?) in $6^{\text {th }}$ National and $5^{\text {th }}$ Mediterranean Morbid Obesity and Metabolic Disorders Congress.

\section{Disclosures}

Ethichs Committee Approval: The Ethics Committee of Elazig Training and Research Hospital provided the ethics committee approval for this study (13281952903.02.01).

Peer-review: Externally peer-reviewed.

Conflict of Interest: None declared.

\section{References}

1. Welbourn R, Pournaras DJ, Dixon J, Higa K, Kinsman R, Ottosson J, et al. Bariatric Surgery Worldwide: Baseline Demographic Description and One-Year Outcomes from the Second IFSO Global Registry Report 2013-2015. Obes Surg 2018;28:313-22. [CrossRef]

2. Kirkil C, Aygen E, Korkmaz MF, Bozan MB. QUALITY OF LIFE AFTER LAPAROSCOPIC SLEEVE GASTRECTOMY USING BAROS SYSTEM. [Article in English, Portuguese] Arq Bras Cir Dig 2018;31:e1385. [CrossRef]

3. Nasta AM, Goel R, Dharia S, Goel M, Hamrapurkar S. Weight Loss and Comorbidity Resolution 3 Years After Bariatric Surgery-an Indian Perspective. Obes Surg 2018;28:2712-9.

4. Hasan MY, Lomanto D, Loh LL, So JBY, Shabbir A. Gallstone Disease After Laparoscopic Sleeve Gastrectomy in an Asian Population-What Proportion of Gallstones Actually Becomes Symptomatic?. Obes Surg 2017;27:2419-23. [CrossRef]

5. Mishra T, Lakshmi KK, Peddi KK. Prevalence of Cholelithiasis and Choledocholithiasis in Morbidly Obese South Indian Patients and the Further Development of Biliary Calculus Disease After Sleeve Gastrectomy, Gastric Bypass and Mini Gastric Bypass. Obes Surg 2016;26:2411-7. [CrossRef]

6. Shaffer EA. Gallstone disease: Epidemiology of gallbladder stone disease. Best Pract Res Clin Gastroenterol 2006;20:981-96. [CrossRef]

7. Brazzelli M, Avenell A, Gillies K, Ramsay C, Ahmed I. Can surgery be avoided in patients with symptomatic gallstone disease and no complications?. BMJ 2019;367:15709.

8. Özdaş S, Bozkurt H. Factors Affecting the Development of Gallstones Following Laparoscopic Sleeve Gastrectomy. Obes Surg 2019;29:3174-8. [CrossRef]

9. Iglézias Brandão de Oliveira C, Adami Chaim E, da Silva BB. Impact of rapid weight reduction on risk of cholelithiasis after bariatric surgery. Obes Surg 2003;13:625-8. [CrossRef]

10. Shiffman ML, Sugerman HJ, Kellum JH, Brewer WH, Moore EW. Gallstones in patients with morbid obesity. Relationship to body weight, weight loss and gallbladder bile cholesterol solubility. Int J Obes Relat Metab Disord 1993;17:153-8.

11. Everhart JE. Contributions of obesity and weight loss to gallstone disease. Ann Intern Med 1993;1 19:1029-35. [CrossRef]

12. Deitel M, Petrov I. Incidence of symptomatic gallstones after bariatric operations. Surg Gynecol Obstet 1987;164:549-52.

13. Guzmán HM, Sepúlveda M, Rosso N, San Martin A, Guzmán F, Guzmán HC. Incidence and Risk Factors for Cholelithiasis After Bariatric Surgery. Obes Surg 2019;29:2110-4. [CrossRef]

14. Dittrick GW, Thompson JS, Campos D, Bremers D, Sudan D. Gallbladder pathology in morbid obesity. Obes Surg 2005;15:238-42. [CrossRef]

15. Manatsathit W, Leelasinjaroen P, Al-Hamid H, Szpunar S, Hawasli A. The incidence of cholelithiasis after sleeve gastrectomy and its association with weight loss: A two-centre retrospective cohort study. Int J Surg 2016;30:13-8. [CrossRef]

16. O'Brien PE, Dixon JB. A rational approach to cholelithiasis in bariatric surgery: its application to the laparoscopically 
placed adjustable gastric band. Arch Surg 2003;138:908-12.

17. Nagem R, Lázaro-da-Silva A. Cholecystolithiasis after gastric bypass: a clinical, biochemical, and ultrasonographic 3-year follow-up study. Obes Surg 2012;22:1594-9. [CrossRef]

18. Caruana JA, McCabe MN, Smith AD, Camara DS, Mercer MA, Gillespie JA. Incidence of symptomatic gallstones after gastric bypass: is prophylactic treatment really necessary?. Surg Obes Relat Dis 2005;1:564-8. [CrossRef]

19. Adams LB, Chang C, Pope J, Kim Y, Liu P, Yates A. Randomized, Prospective Comparison of Ursodeoxycholic Acid for the Prevention of Gallstones after Sleeve Gastrectomy. Obes Surg 2016;26:990-4. [CrossRef]

20. Zhang FM, Yu CH, Chen HT, Shen Z, Hu FL, Yuan XP, et al. Helicobacter pylori infection is associated with gallstones: Epidemiological survey in China. World $\mathrm{J}$ Gastroenterol 2015;21:8912-9. [CrossRef]

21. Takahashi $Y$, Yamamichi N, Shimamoto T, Mochizuki S, Fujishiro $M$, Takeuchi $C$, et al. Helicobacter pylori infection is positively associated with gallstones: a large-scale crosssectional study in Japan. J Gastroenterol 2014;49:882-9.
22. Mason EE, Renquist KE. Gallbladder management in obesity surgery. Obes Surg. 2002;12:222-9. [CrossRef]

23. Wudel LJ Jr, Wright JK, Debelak JP, Allos TM, Shyr Y, Chapman WC. Prevention of gallstone formation in morbidly obese patients undergoing rapid weight loss: results of a randomized controlled pilot study. J Surg Res 2002;102:50-6. [CrossRef]

24. Tsirline VB, Keilani ZM, El Djouzi S, Phillips RC, Kuwada TS, Gersin K, et al. How frequently and when do patients undergo cholecystectomy after bariatric surgery? Surg Obes Relat Dis 2014;10:313-21. [CrossRef]

25. Raziel A, Sakran N, Szold A, Goitein D. Concomitant cholecystectomy during laparoscopic sleeve gastrectomy. Surg Endosc 2015;29:2789-93. [CrossRef]

26. Sioka E, Zacharoulis D, Zachari E, Papamargaritis D, Pinaka O, Katsogridaki $\mathrm{G}$, et al. Complicated gallstones after laparoscopic sleeve gastrectomy. J Obes 2014;2014:468203. [CrossRef]

27. Sugerman $H J$, Brewer WH, Shiffman ML, Brolin RE, Fobi MA, Linner $\mathrm{JH}$, et al. A multicenter, placebo-controlled, randomized, double-blind, prospective trial of prophylactic ursodiol for the prevention of gallstone formation following gastric-bypass-induced rapid weight loss. Am J Surg 1995;169:91-6. 